\title{
Cervical tuberculous lymphadenitis in an elderly adult
}

\author{
Elizaveta Kalaidina, Christopher Holbrook
}

Department of Internal Medicine, Presence Saint Joseph Hospital, Chicago, Illinois, USA

\section{Correspondence to} Dr Elizaveta Kalaidina, elizaveta.kalaidina@gmail.com

Accepted 17 July 2018

\section{DESCRIPTION}

A 94-year-old man presented with complaints of increasing fatigue and generalised weakness for 1 month's duration. On admission, the patient had tachycardia of $112 \mathrm{bpm}$ and fever of $101.1^{\circ} \mathrm{F}$. His initial physical examination was otherwise normal. Lactic acid was elevated $(4.13 \mathrm{pg} / \mathrm{mL})$, but other laboratory markers were within normal limits. No apparent source of infection was identified by initial urinalysis, chest radiography or CT of the abdomen without contrast. The lactic acidosis resolved after administration of normal saline, but he continued to have fever, which prompted more thorough physical examination that revealed a painless rightsided neck mass. CT of the neck without contrast confirmed a low-density neck mass in the right posterior cervical region measuring $7 \mathrm{~cm}$ in the maximum diameter (figures 1 and 2), suspicious for necrotic tumour or an abscess. Ultrasound-guided drainage of the mass recovered $50 \mathrm{~mL}$ of purulent material that was submitted for microbiological analysis and cytology. The sample contained inflammatory cells and debris, but was negative for malignancy. Numerous acid-fast bacilli (AFB) were identified on AFB smear, and the patient was started on the quadruple antituberculous regimen of isoniazid, rifampin, pyrazinamide and ethambutol based on high clinical suspicion for Mycobacterium tuberculosis. PCR and sputum AFB cultures ultimately confirmed the presence of M. tuberculosis, and

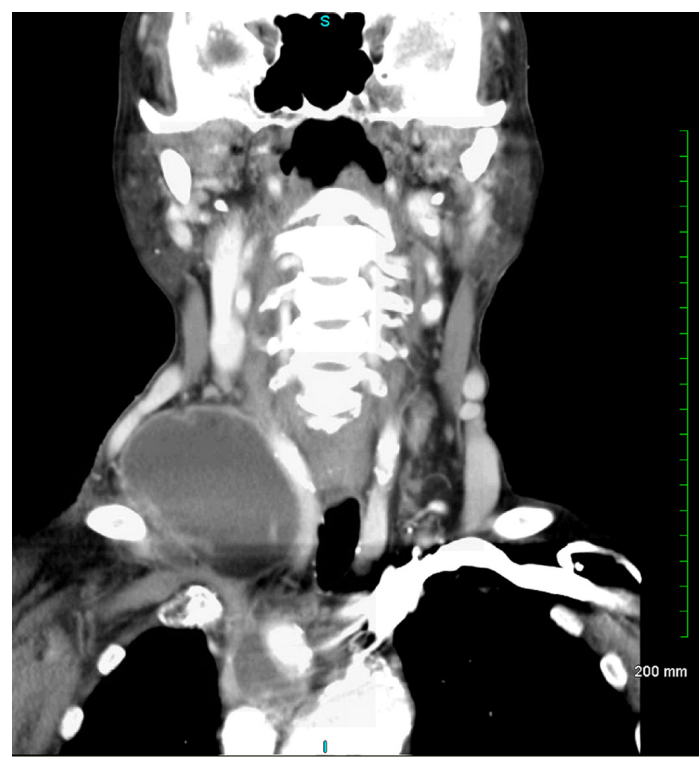

Figure 1 Coronal CT image of the neck reveals a large low-density mass in the right posterior cervical region measuring $7.6 \times 6.5 \times 6.7 \mathrm{~cm}$. The mass is compressing the right internal jugular vein and displacing the trachea and thyroid gland.
Learning points

- Cervical tuberculous lymphadenitis, previously known as scrofula, represents the most common form of extrapulmonary tuberculosis and should be considered in all patients with cervical lymphadenopathy. The disease is typically caused by reactivation of latent mycobacteria found within the lymph nodes that were seeded during primary infection. The clinical presentation is often indolent, featuring a painless, slowly enlarging, unilateral cervical mass. Constitutional symptoms such as fever, fatigue, weight loss and night sweats are often absent in immunocompetent individuals. The disease has a predilection for young adults and females, in contrast to pulmonary tuberculosis (TB), which is more common in older men. In developed nations, prevalence is highest among immigrants from endemic regions and immunocompromised patients, including the HIV-infected population. Both pulmonary and extrapulmonary TB have been increasing in incidence over the past few decades, largely in part due to the rise of HIV.

- A number of diagnostic techniques are available for diagnosis of tuberculous lymphadenitis. Imaging modalities such as ultrasound, CT or MRI of the neck are often used for initial evaluation of lymphadenopathy. Fine-needle aspiration of the affected lymph nodes is the preferred diagnostic procedure due to its relative ease, minimally invasive nature and cost-effectiveness. The Infectious Disease Society of America recommends that specimens undergo acid-fast bacilli smear microscopy, histological examination, mycobacterial culture with sensitivity testing and nucleic acid amplification testing. Histology may reveal granulomatous inflammation with or without caseating necrosis. Definitive diagnosis of tuberculosis can be established by culture or PCR demonstrating Mycobacterium tuberculosis in the affected lymph node. Tuberculin skin test and interferon-gamma release assay can be used as ancillary tests.

no resistance to rifampin was reported. HIV test was negative. On further questioning, the patient and his family members denied any contacts with persons with known or suspected tuberculosis. The patient had never been diagnosed with or treated for tuberculosis in the past. He was born in Japan and immigrated to the USA decades earlier. The treatment resulted in significant decrease in size 


\section{Learning points}

Diagnosis of TB in the elderly population is particularly challenging. Clinical features of TB in this group are often non-specific or atypical, and the disease can often go unrecognised. A significant delay in diagnosis and initiation of anti-TB therapy ( 22 days vs 13 days) has been reported in elderly patients compared with their younger counterparts. In the USA, as well as worldwide, the elderly bear the highest burden of TB among all other age groups (incidence rate of 4.6 cases per 100000 in 2016). Foreign-born individuals are disproportionally affected by TB, both in the general population as well as in the elderly, with a twofold increase in prevalence compared with their native-born counterparts. Among older adults of all ethnic groups/races, Asians have the highest case rate, with 44.7 cases per 100000 . Difficulties in diagnosis contribute to a higher mortality rate from TB in the elderly. However, if early diagnosis is achieved and appropriate treatment is initiated, the prognosis for recovery is good.

of lymphadenopathy without any significant toxicity. However, despite these reassuring initial observations, the patient continued to deteriorate over the subsequent weeks. Given his overall poor prognosis, medical care was transitioned to hospice and the patient passed away shortly thereafter.

Contributors EK and $\mathrm{CH}$ were equally involved in the concept, literature review and compilation of this case report.

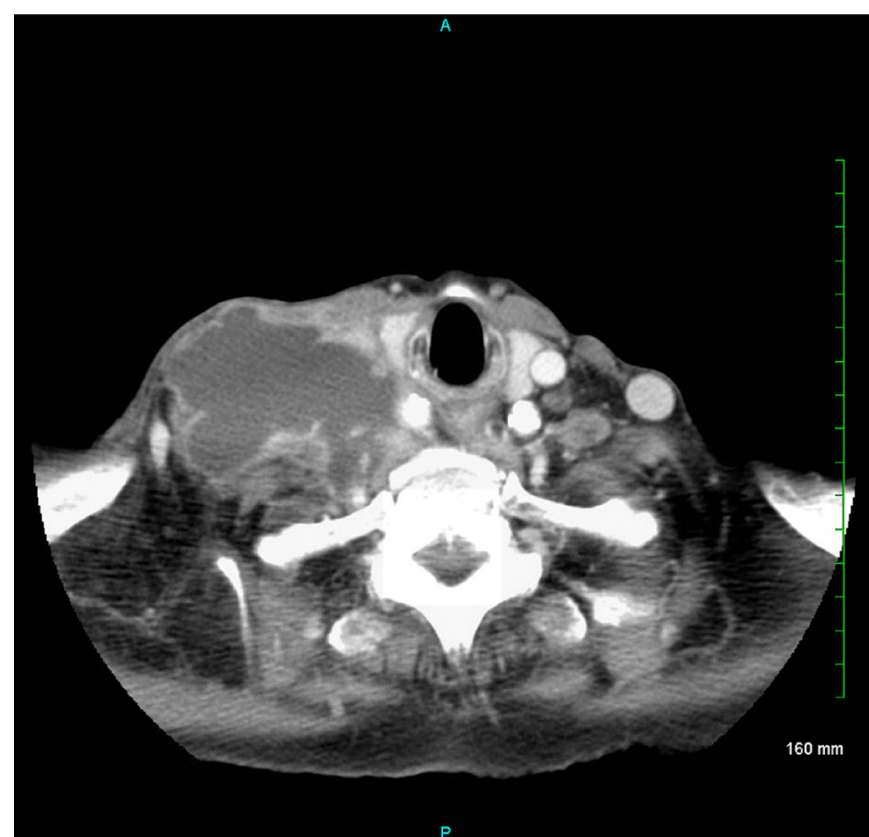

Figure 2 Transverse CT image of the right posterior cervical neck mass.

Funding The authors have not declared a specific grant for this research from any funding agency in the public, commercial or not-for-profit sectors.

Competing interests None declared.

Patient consent Obtained.

Provenance and peer review Not commissioned; externally peer reviewed.

Copyright 2018 BMJ Publishing Group. All rights reserved. For permission to reuse any of this content visit

http://group.bmj.com/group/rights-licensing/permissions.

BMJ Case Report Fellows may re-use this article for personal use and teaching without any further permission.

Become a Fellow of BMJ Case Reports today and you can:

- Submit as many cases as you like

- Enjoy fast sympathetic peer review and rapid publication of accepted articles

- Access all the published articles

- Re-use any of the published material for personal use and teaching without further permission

For information on Institutional Fellowships contact consortiasales@bmjgroup.com

Visit casereports.bmj.com for more articles like this and to become a Fellow 